\title{
1. Irrigation System through Intelligent Agents Implemented with Arduino Technology
}

\author{
Rodolfo Salazar ${ }^{\mathrm{a}}$, Jose Carlos Rangel ${ }^{\mathrm{a}}$, Cristian Pinzón ${ }^{\mathrm{a}}$, Abel \\ Rodríguez ${ }^{\mathrm{b}}$ \\ ${ }^{a}$ Faculty of Computer Systems Engineering, Technological University of Panamá \\ b Faculty of Electrical Engineering, Technological University of Panamá
}

KEYWORD

Fuzzy logic

Software agents

Automated irrigation

Multi-agents systems

Arduino

\section{Introduction}

Water is a scarce resource but essential for life: only about $1 \%$ of the planet's water is fresh and accessible to the population [GUJARRO, M. et $a l .$, 2007]. The fountains, springs, river, etc. are in danger of extinction accelerated due to changes in climate and soil but mainly due to human deforestation, pollution and inefficient use of water [GUJARRO, M. et al., 2007].

The agricultural sector is the largest consumer of water with $65 \%$, one of the main factors that influence is the use of inefficient irrigation systems [TOLOZA, J. et al., 2006]. In this situation, it is necessary to explore new lines of research aimed at improving the use of water in irrigation systems used in agriculture.

In recent years have seen the first applications of the field of Artificial Intelligence (AI) applied to agriculture. AI can be defined as the science that aims to design and build machines that can mimic human intelligent behavior [VECINO, J., 1989].

The use of AI (computer vision, robotics, control, expert systems, decision support systems, etc.) and other promising techniques of AI (neural networks, fuzzy logic, genetic algorithms, and bioinformatics) are routed providing solutions to problems in agricultural systems effectively complex [BUSTOS, J., 2005]. In this paper we present a smart irrigation system based on agents using fuzzy logic and low-cost Arduino technology. This system uses techniques from the field of AI such as Fuzzy Logic and Intelligent Agents for monitoring and control of irrigation mechanism.

With the use of a smart irrigation system is possible to monitor in real time the specific needs of water for each crop, taking into account certain characteristics of the soil. This will allow more accurate use water in agriculture projects, thus avoiding the excessive use of this valuable resource.

Is presented below the problems surrounding current irrigation systems. Subsequently describes the fuzzy logic-based technologies, agents and multi-agent systems. Then we describe the architecture of a multi-agent system for monitoring and intelligent control of an irrigation system. Finally, we present preliminary results and conclusions. 


\section{Material and methods}

\subsection{Intelligent Agents}

A multi-agent system is basically a set of autonomous agents able to work together to solve problems [WOOLRIDGE and WOOLRIDGE, 2002]. These systems must meet certain conditions in order to be classified as such. At least one of the agents must be autonomous and there must be at least a relationship between two agents, wherein one of them satisfies one of the objectives of the other. Furthermore, any of the agents should possess a limited ability to solve the problem independently [BRATMAN, M., 1987]

The way agents are decomposed into a set of modules and how these modules interact to achieve the required functionality, is given by the selected agent architecture [WOOLRIDGE and WOOLRIDGE, 2002].

The model presented in this paper uses deliberative architecture, which manages a symbolic representation of the real world, where an agent's decisions are based on logical reasoning based on pattern matching and symbolic manipulation, starting from an initial state and a set of plans with a purpose to fulfill. Within deliberative architectures lies the BDI (Believe, Desire, Intention), based on mental aptitudes, using beliefs, desires and intentions [RAO and GEORGEFF, 1991] [BRATMAN, M., 1987].

We can infer some features about the behavior of the agents [MAS, A., 2005]:

- Continuous and autonomous.

- Communication

- Robustness.

- Adaptability.

The use of intelligent agents, from the focus of a multi-agent architecture, will allow the monitoring and control of the irrigation system. By their own innate characteristics of the agents, these tasks are structured in roles of agents, which are more detailed hasten. The following describes the fuzzy logic technology and Arduino used in the Project.

\subsection{Fuzzy Lógic}

Fuzzy logic or fuzzy (Fuzzy Logic) [ZADEH, L., 1988] has emerged as a lucrative tool for controlling subsystems and complex industrial processes, as well as for entertainment and home electronics, diagnosis systems and other expert systems. With this logic is intended rigorously represent the meaning of natural language statements inaccurate.

Fuzzy logic is focused on that, differently from classical logic systems, focuses on the modeling of imprecise modes of reasoning, which play an essential role in the remarkable human ability to draw rational decisions in an environment of uncertainty and imprecision. This ability depends, however, on our ability to infer an approximate answer questions based on a set of knowledge that is inaccurate, incomplete or not totally reliable "[ZADEH, L., 1988].

Fuzzy logic allows us to represent common knowledge, which is mostly in the linguistic quality and not necessarily quantity, in a mathematical language, through fuzzy set theory that generalizes the classical set theory.

Fuzzy logic is basically a multi-evaluated logic that allows intermediate values to define conventional evaluations as yes / no, true / false, black / white, etc.. Notions like "rather hot" or "luck" can be formulated mathematically and processed by computers. In this way an attempt was made to apply a more humane way of thinking about computer programming. Fuzzy logic was initiated in 1965 by Lotfi Asker Zadeh, a professor of computer science at the University of California at Berkeley [ZADEH, L., 1988].

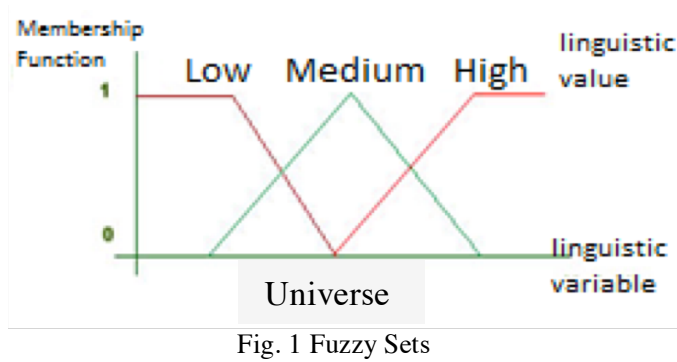

A fuzzy set $\mu$ on a universe $\mathrm{X}$ assigns a degree of membership of each element in the range $[0$, 
$1]$, and not in the set $\{0,1\}$ as classical sets, which happen to be a particular case of fuzzy sets.

\subsection{Arduino Platform}

Arduino is an open electronic platform for prototyping, based on flexible software and hardware that allows to make projects in a quick and easy way [ARDUINO, 2012].

Arduino can take information from the environment through their input mechanisms (pins), of a variety of sensors and can affect that surrounds controlling lights, motors, and other actuators.

The microcontroller on the Arduino board is programmed using the Arduino programming language and the Arduino development environment. Their projects can be run without connecting to a computer, while having the ability to do it and communicate with different types of software.

There are many different versions of Arduino boards. For the project presented in this work was selected the Arduino MEGA [ARDUINO MEGA, 2013] to control the sensors and actuators because it has a microcontroller ATmega1280 [ARDUINO MEGA, 2013]. This board has 54 digital inputs / outputs, 16 analog inputs. Arduino Mega also facilitates communication with various aspects of the computer, another Arduino and other microcontroller if necessary.

In this project, the Arduino selected will be responsible for receiving all the information from sensors, and send it to a computer by serial communication. After receiving this information, it is processed by intelligent agents installed in a multi-agent architecture residing on a computer. Depending on the received data, and reasoning mechanism based on fuzzy logic, the Arduino turns on or off the irrigation system.

\subsection{Multi-Agent Architecture}

This section describes the multi-agent architecture that was built for the project development. This has been developed on the base development platform for agents JADE [JADE, 2012]. This agent platform is based on the FIPA standard [FIPA, 2013] for modeling Multi-Agent system environments.

For the development of this project proposes a multi-agent architecture using agent types. Each type of agent has an assigned role that identifies the tasks. Figure 2 shows the build agents architecture.

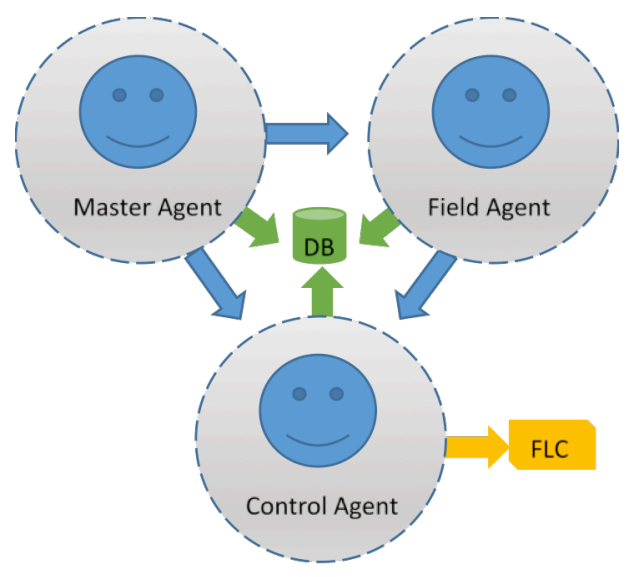

Fig. 2 Multi-Agent Architecture

The following describes the types of agents and the assigned role.

- Master Agent: Agent responsible for monitoring the database and retrieve information. This agent sends a message to the Agent field to begin the task of monitoring. Basically it is the type of agent that activates the system.

- $\quad$ Field Agent: this agent receives messages from the Master Agent. Received a message, the field agent retrieves the values of the sensors that were sent to a database, groups these values and sends a message to the Control Agent. Field Agent is responsible for monitoring the values collected by the sensors installed in the field, normalize these values and send control agent for evaluation. 
- Control Agent: Deliberative agent. Receives a message from Field Agent. This agent incorporates into its internal structure reasoning mechanism based on fuzzy logic model. This agent receives active values and fuzzy control mechanism to determine the activation or not of the irrigation system.

The following explains the mechanism built into the agent fuzzy control.

\subsection{Fuzzy Mechanism}

We propose to use a system MISO (multiple input, single output) [DEL BRIO, 2006], since it will have $n$ inputs and a single output.

The deciding factor in the decision of the system is the soil moisture variable. This moisture is regularly monitored by sensors that are distributed in the field.

From these moisture values linguistic variables are created.

Linguistic variables are responsible for naming each of the fuzzy sets. The target is expressed in natural language each of the values of the fuzzy sets.

\begin{tabular}{|l|l|}
\hline \multicolumn{1}{|c|}{ Fuzzy Set } & Natural Language \\
\hline NW $=\mathbf{0}$ & Not Wet \\
\hline BW $=\mathbf{2 0 5}$ & Bit Wet \\
\hline $\mathbf{W}=\mathbf{4 1 0}$ & Wet \\
\hline VW $=\mathbf{6 1 5}$ & Very Wet \\
\hline TW $=\mathbf{8 2 0}$ & Too Wet \\
\hline \multicolumn{2}{|c|}{ Table 1 Linguistic Variables used for the definition of } \\
\hline
\end{tabular}
fuzzy sets

The following describes the triangular type membership functions for the input variables.

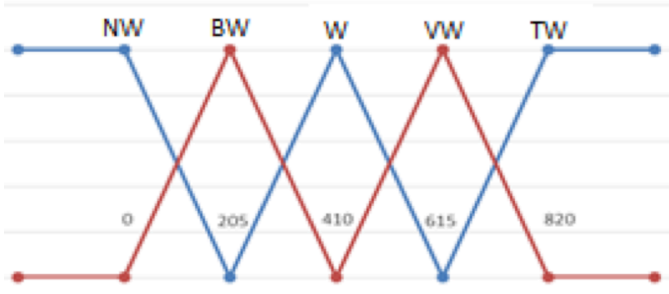

Fig. 3 Membership functions

After this proceeds to create the rule base. To describe the rules can make use of a Fuzzy Associative Memory (FAM).

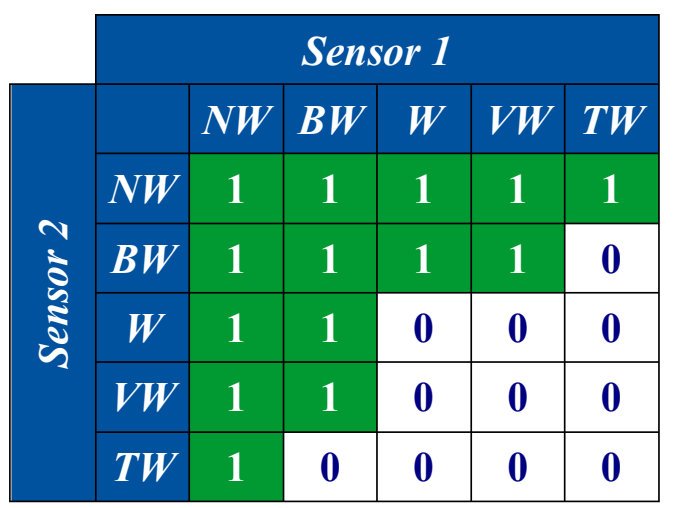

Table. 2 FAM for irrigation control. Each combination is associated with a rule.

\subsection{Software Tool}

Is presented below interface software tool (Figure 4) for capturing data from the sensors.

This tool creates the connection with Arduino. With this connection you can see important details such as the values are getting moisture sensors, or know if the irrigation system is activated or not.

The interface of this software technology is designed using Windows Presentation Foundation (WPF) [WPF, 2012].

The software has two modes, automatic and manual.

- Manual Mode: Allows manual control of the irrigation system. In this mode is deactivated intelligent components, irrigation is started and stopped by a person.

- Automatic mode: In this mode activates all system intelligent components so that it can act 
and decide without human supervision. The system at first run starts in this mode.

Additional were used programming platforms JADE [JADE, 2012], NetBeans [NETBEANS, 2013], Arduino IDE [ARDUINO IDE, 2013] Visual Studio [VISUAL STUDIO, 2012] and Microsoft Access [MICROSOFT ACCESS, 2012].

Controlling moisture sensors monitoring is under Arduino MEGA [ARDUINO MEGA, 2013]. The system controller is developed in the Arduino IDE environment

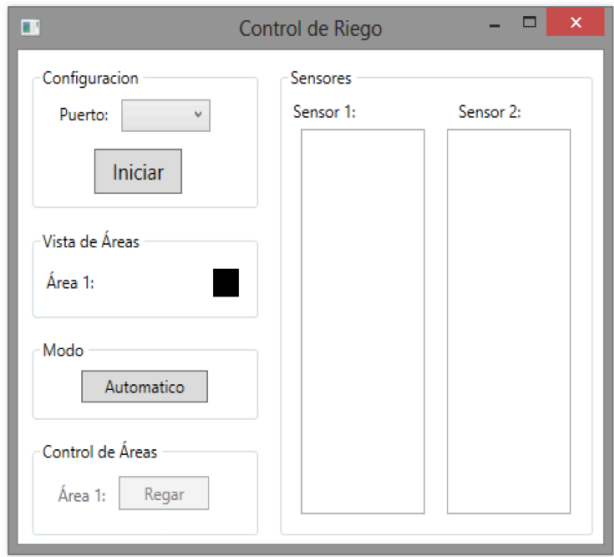

Fig. 4 Irrigation System Software Interface

\subsection{System Implementation}

The system test was done with a project of Taiwanese guavas, developed at the university. In the prototype used an Arduino along with a number of sensors which monitor the status of the plants (moisture). It also has actuators that are responsible for providing the necessary water to plants.

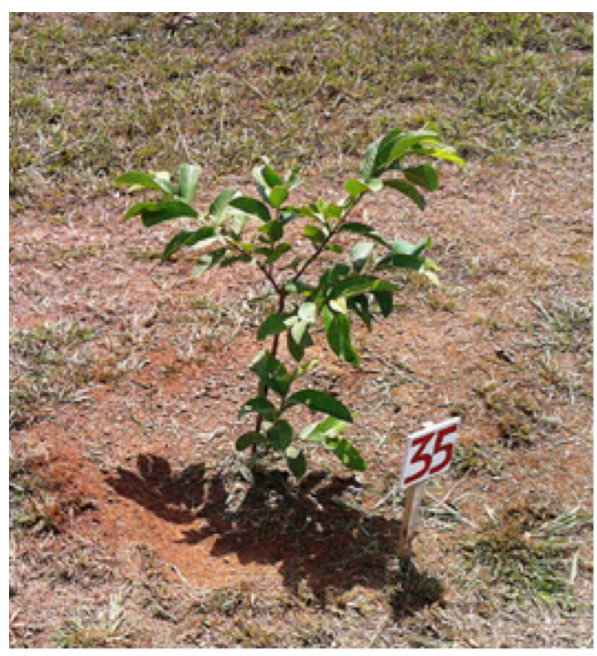

Fig. 5 Taiwanese guava saplings

The first tests of the system were carried out in 2 lines of 10 saplings each. In Fig. 6 used common irrigation system, in which a person were watered once a day saplings. In Fig. 7 used smart irrigation system with agent technology.

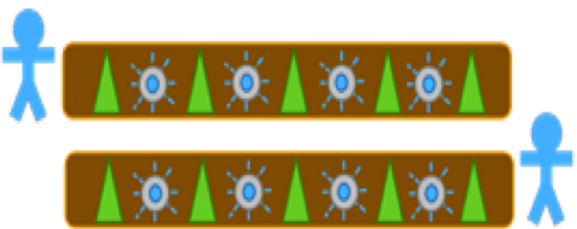

Fig. 6 Arrangement of saplings with common irrigation system (line 1)

The Arduino is programmed to monitor the moisture sensors. If it detects that the plot has low humidity levels according to the rules, the Master Agent sends the order to the activation of the irrigation system. In this way, real time controls the humidity actually require cultivation, thus preventing the excessive use of water. 


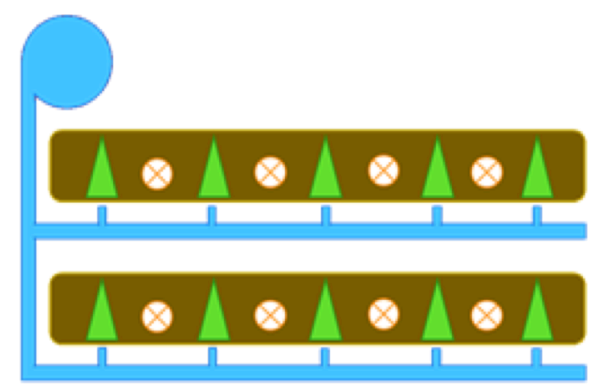

Fig. 7 Arrangement of saplings controlled by the Smart Irrigation System (line 2)

\section{Results}

The project is in a prototype stage and performing the first tests. These are testing different types of sensors to obtain actual data field conditions, in this case moisture. Additional is the development of an expert module that takes into account other features like crop types, soil characteristics such as texture, permeability, moisture retention, slope, etc...

\section{Conclusions}

Until now the basic results obtained have demonstrated the following:

- It can improve water use, real-time monitoring ground conditions.

- To give, the crops the amount of water that is actually required for proper development.

- Frees human resource from repetitive tasks having an autonomous system able to monitor soil moisture conditions and enable/disable the mechanism irrigation when needed.

The research project is in its early stages of design, development and testing. Is expected in the coming months to continue testing for more accurate results and demonstrate their application in different scenarios. 


\section{References}

[GUJARRO, M. et al., M. Guijarro Mata-Garcia, E. Tortajada Agudo and F. González Rivas, "Sistema de 2007]

Riego Inteligente Borroso,” 2007.

[TOLOZA, J.et al., 2006] J. Toloza, L. Leiva, A. Riba, F. Carmona and N. Acosta, Desarrollo de un prototipo de sistema portátil para la detección en tiempo-real de la necesidad de riego en cultivos de producción intensiva, 2006.

[VECINO, J., 1989] J. Vecino, "La Inteligencia Artificial en la Agricultura: Perspectivas de los Sistemas Expertos," Revista de Estudios Agro-Sociales, 1989.

[BUSTOS, J., 2005] J. R. Bustos M., "Inteligencia Artificial en el Sector Agropecuario," Seminario de Investigación I, 2005.

[WOOLRIDGE and M. Woolridge and M. Wooldridge, in Introduction to Multiagent Systems. WOOLRIDGE, 2002] JohnWiley \& Sons, Inc., New York, 2002.

[BRATMAN, M., 1987] M. Bratman, in Intention, Plans, and Practical Reason. Harvard University Press, Cambridge, MA , Harvard University Press, Cambridge, MA , 1987.

[RAO and GEORGEFF, A. Rao and M. Georgeff, Modeling rational agents within a BDI1991] architecture., San Mateo, CA, USA: Morgan Kaufmann publishers Inc., 1991.

[MAS, A., 2005] A. Mas, "Agentes Software y Sistemas Multi-Agente: Conceptos, Arquitecturas y Aplicaciones.," in Agentes Software y Sistemas MultiAgente: Conceptos, Arquitecturas y Aplicaciones., Madrid, Pearson Prentice Hall, 2005, p. 296.

[ZADEH, L., 1988 ] ～～L. Zadeh, "Fuzzy Logic," IEEE Computer Magazine, abril, 1988.

[ARDUINO, 2012] ARDUINO, “Arduino.cc," 2012. [Online]. Available: http://arduino.cc/en/Main/Software.

[ARDUINO MEGA, Mega, “ARDUINO MEGA,” 2013 [Online]. Available: 2013] http://arduino.cc/es/Main/ArduinoBoardMega

[JADE, 2012]

JADE, “Java Agent DEvelopment Framework,” 2012 [Online]. Available: http://jade.tilab.com/.

[FIPA, 2013]

FIPA, "Foundation for Intelligent Physical Agents," 2013 [Online]. Available: http://fipa.org/.

[DEL BRIO, 2006] A. S. B. del Brio, Redes Neuronales y Sistemas Borrosos, Madrid: RAMA, 2006

[ WPF, 2012] WPF, "Windows Presentation Fundation," 2012 [Online]. Available: http://msdn.microsoft.com/es-es/library/ms742119.aspx.

[ NETBEANS, 2013] NetBeans, “NetBeans IDE,” 2013 [Online]. Available: https://netbeans.org/.

[ARDUINO IDE, 2013] Arduino, “Arduino IDE,” 2013 [Online]. Available: http://arduino.cc/es/Main/Software.

[VISUAL STUDIO, Microsoft, "Microsoft Visual Studio," 2012 [Online]. Available: 2012] http://www.microsoft.com/visualstudio/esn/2013-preview. 
